\title{
Vorwort zur dritten Auflage.
}

Neu aufgenommen sind einige Anwendungen der Phasenlehre; das Kapitel der radioaktiven Elemente ist völlig umgearbeitet und vervollständigt worden. Die neue Spektraltafel, die in der zweiten Auflage gebracht worden ist, wurde nach den in dem niederländischen Lehrbuch der Physik von Bosscha-Sissirgir enthaltenen Tafeln zusammengestellt, doch hat sich ergeben, daB diese aus H. ERDManN übernommen sind. Auch einige technische Prozesse sind neu erwähnt. Es herrscht Meinungsverschiedenheit darüber, ob man solche in ein elementares Lehrbuch überhaupt aufnehmen soll. Freilich haben diejenigen Recht, welche behaupten, daB es unmöglich ist, alle diejenigen technischen Prozesse zu erwähnen, die zurzeit in Gebrauch sind. Doch wird es auch wohl niemand einfallen, nach der Beschreibung eines technischen Prozesses in einem elementaren. Buch in der Praxis zu arbeiten. Der Zweck der Aufnahme ist vielmehr, als ausgezeichnete Beispiele von chemischen Umsetzungen, bisweilen auch von physikalisch-chemischen Problemen zu dienen. So aufgefaßt, ist es gleichgültig, ob der mitgeteilte Prozeb noch allgemein angewendet wird oder eben durch einen anderen verdrängt ist.

Von meinem Lehrbuch ist inzwischen auch eine englische, italienische und russische Übersetzung erschienen.

Herr Prof. MaNchor ist leider verhindert, sich an der Bearbeitung der deutschen Ausgabe weiter zu beteiligen.

Groningen (Niederlande), November 1904.

A. F. Holleman 